\title{
Representasi Ketidaksetaraan Gender pada Serial Drama 13 Reasons Why (Analisis Wacana Kritis Van Dijk)
}

\author{
Reginald Gusli, Wulan Purnama Sari \\ reginaldgerardo@gmail.com,wulanp@fikom.untar.ac.id
}

Fakultas Ilmu Komunikasi, Universitas Tarumanagara Jakarta

\begin{abstract}
This study is a careful study to find out that there is a message of gender inequality in social reality on the Netflix Original Series entitled 13 Reasons Why. The research method that I use here is to use qualitative methods. Research techniques are using Van Djik's critical discourse analysis techniques. Data collection techniques using observation techniques. Observations were made with observations by the author of 13 Reasons Why and watched the series in detail to capture any events related to the topic of analysis. From the observations made by the author, the narration of events and scene footage clearly shows the elements of gender inequality and is also supported by gender theory which is associated with the characteristics of Van Djik's discourse analysis, so that the research conducted has results that strengthen the hypothesis of the author.
\end{abstract}

Keyword : 13 reasons why, critical discourse analysis, gender inequality, Netflix.

\begin{abstract}
Abstrak
Penelitian ini penulis teliti bertujuan untuk mengetahui bahwa adanya pesan ketidaksetaraan gender dalam realitas sosial pada Netflix Original Series berjudul 13 Reasons Why. Metode penelitian yang penulis pakai disini adalah dengan menggunakan metode kualitatif. Teknik penelitian memakai teknik analisis wacana kritis Van Dijk. Teknik pengumpulan data menggunakan yaitu teknik observasi. Observasi dilakukan dengan kegiatan pengamatan yang penulis lakukan terhadap 1 Reasons Why dan menyaksikan serial tersebut secara detail untuk menangkap peristiwa yang terkait dengan topik analisis. Dari hasil pengamatan yang penulis lakukan, narasi peristiwa dan cuplikan adegan memperlihatkan jelas mengenai unsur ketidaksetaraan gender tersebut dan juga didukung oleh teori gender yang dikaitkan dengan karakteristik dari analisis wacana Van Dijk, sehingga penelitian yang dilakukan memiliki hasil yang memperkuat hipotesis dari penulis.
\end{abstract}

Kata Kunci: 13 reasons why, analisis wacana kritis, ketidaksetaraan gender, Netflix.

\section{Pendahuluan}

Dunia media digital saat ini semakin berkembang pesat dengan banyaknya inovasi-inovasi baru yang dapat membuat masyarakat semakin tertarik untuk mengikutinya, salah satunya yaitu dalam hal menonton suatu hiburan. Tren menonton kini telah bergeser dari film-film di bioskop, ataupun berita di televisi, menjadi menonton lewat media digital atau online, yang bisa diakses dimanapun dan kapanpun orang itu berada, selama terhubung dengan adanya internet. Diawali dengan munculnya Youtube sebagai layanan video streaming pertama yang muncul dan memberikan hiburan bagi masyarakat, Netflix pun mulai muncul dengan pengembangan akan layanan video streaming menjadi layanan streaming untuk film dan serial televisi. 
Setelah adanya layanan streaming Netflix, terbentuklah suatu fenomena yang cukup unik di tengah masyarakat, yaitu fenomena yang disebut binge watching. Binge watching merupakan fenomena baru dimana orang menyaksikan satu jenis atau judul tayangan tertentu secara berkelanjutan dalam jangka waktu yang cukup lama (kompasiana.com, 2016). Jumlah pelanggan Netflix pun tidak sedikit, tercatat pada tahun 2018 berdasarkan laporan penyedia solusi smart broadband, Sandvine, menyatakan fakta bahwa Netflix telah menjadi layanan internet yang paling besar trafik globalnya dalam hal penyedia layanan video streaming mengalahkan Youtube (Tribunnews.com, 2019).

Netflix mengusung tagline "See What's Next" yang membuat pelanggan tetap setia dengan layanan Netflix. Karena tagline tersebut mengisyaratkan bahwa Netflix akan selalu memunculkan sesuatu yang baru dan membuat rasa penasaran di benak penonton sehingga akan terus mengikuti perkembangan yang ada di Netflix. Di Netflix pun terdapat salah satu fitur dan konten eksklusi yang hanya ada di Netflix serta membuat pelanggan merasakan pengalaman yang berbeda setiap harinya, yaitu Netflix Original Series.

Netflix Original Series merupakan serial-serial yang dibuat oleh Netflix secara eksklusif dengan beragam judul dan genre sehingga pelanggan memiliki banyak pilihan sesuai dengan seleranya masing-masing. Netflix Original Series memiliki perbedaan dengan tayangan lainnya, selain Netflix Original Series tidak dapat diakses di layanan streaming lainnya, Netflix Original Series memiliki rata-rata tayangan dengan pesan yang lebih dalam dari tayangan lain, dan juga banyak yang berkaitan dengan realitas sosial masa kini.

Netflix Original Series yang memiliki pesan mendalam dalam setiap serialnya sangat berpotensi untuk merubah pola pikir penontonnya ke arah yang lebih baik, ditambah lagi dengan jumlah pelanggannya yang tidak sedikit, maka penyampaian pesan pun dapat terjangkau oleh banyak orang. Jika melihat judul serial yang sampai sekarang cukup populer dan memiliki pesan yang mendalam, penulis memilih satu judul, yaitu "13 Reasons Why". 13 Reasons Why merupakan salah satu Netflix Original yang sempat menjadi perbincangan dan menuai kontroversi di tengah masyarakat dikarenakan oleh isi konten di dalamnya yang relatif sensitif bagi sebagian orang.

Di latar belakangi oleh kehidupan remaja masa kini, 13 Reasons Why menceritakan adanya kasus bunuh diri yang dilakukan oleh seorang siswi SMA bernama Hannah Baker. Setelah peristiwa bunuh diri yang dilakukan oleh Hannah Baker, teman-teman dari Hannah Baker mulai menerima paket berisikan kaset pita yang memperdengarkan dan membuka 13 alasan penyebab Hannah akhirnya melakukan bunuh diri.

Dalam Season 1 yang penulis telah saksikan dari episode 1 sampai 13, terdapat banyak pesan dan makna yang disampaikan lewat serial ini, mulai dari pesan moral, sosial, hubungan, dan lainnya. Tetapi disini penulis menemukan 1 makna yang menarik untuk dibahas, dan tidak banyak orang yang menyadari pesan tersebut, yaitu pesan mengenai ketidaksetaraan gender. Orang-orang yang menonton serial ini mungkin akan lebih melihat pesan sosial yang menceritakan perundungan di lingkungan sekolah, padahal terdapat sisipan pesan mengenai ketidaksetaraan gender yang menarik untuk diulas lebih dalam. 
Di masa yang sekarang ini, khususnya di Indonesia, pesan tersebut cukup berkaitan dengan realitas kehidupan masyarakat sosial masa kini. Walaupun sudah terdapat sejarah mengenai emansipasi wanita yang diperjuangkan oleh R.A Kartini, tetapi masih banyak kasus-kasus dan permasalahan ketidaksetaraan gender yang terjadi, dan dari semua kasus yang telah ada, perempuan lah yang paling sering menerima perlakuan yang tidak setara. Seperti contohnya, terdapat kasus dimana perempuan mengalami pelecehan seksual, tetapi pada akhirnya perempuanlah yang disalahkan karena memakai pakaian yang minim dan menunjukan bentuk tubuhnya.

Latar belakang yang telah dijabarkan tersebut membuat penulis akhirnya ingin menganalisa Netflix Original Series 13 Reasons Why dengan judul "Representasi Ketidaksetaraan Gender Pada Netflix Original Series 13 Reasons Why ( wacana kritis )". Dikarenakan oleh banyaknya pelanggan dan penonton, maka diharapkan agar pesan mengenai ketidaksetaraan gender ini bisa tersampaikan dengan efektif dan dipahami oleh para penonton, sehingga pandangan penonton dapat berubah mengenai pesan yang ingin disampaikan. Penelitian ini juga menjadi lebih menarik karena pesan yang sebetulnya ditonjolkan yaitu perundungan, tetapi penulis ingin menguji lebih dalam untuk membuktikan bahwa terdapat isu ketidaksetaraan gender di Netflix Original Series 13 Reasons Why.

Berdasarkan uraian diatas, maka dapat dirumuskan masalah sebagai berikut : "Bagaimana unsur ketidaksetaraan gender diperlihatkan atau dihadirkan melalui cerita dengan sudut pandang generasi muda?" dan "Bagaimana unsur ketidaksetaraan gender diimplementasikan dalam sebuah Netflix Original Series berjudul 13 Reasons Why?".

Penulis mengambil contoh penelitian terdahulu untuk mendukung dan memperkuat hasil uji dari penelitian ini, salah satunya yaitu dari penelitian terdahulu yang dilakukan Olivia Kurniawan dari Fakultas Ilmu Komunikasi Universitas Tarumanagara, berjudul Analisis Wacana Nasionalisme Dalam Film $5 \mathrm{~cm}$. dari penelitian terdahulu itu penulis mendapatkan banyak referensi, mulai dari teori, metode, dan format penelitian yang sangat membantu penulis dalam penelitian kali ini. Konsep teori yang penulis gunakan dalam penelitian ini antara lain yaitu dengan menggunakan teori karakteristik pada teknik analisis wacana kritis Van Dijk yang dihubungkan dengan teori ketidaksetaraan gender, sehingga wacana akan ketidaksetaraan gender akan semakin kuat hasil ujinya.

\section{Metode Penelitian}

Penelitian ini dimaksudkan untuk membuktikan bahwa terdapat makna ketidaksetaraan gender pada Netflix Original Series berjudul 13 Reasons Why melalui peristiwa dan adegan yang ada dalam serial tersebut, sehingga dari rumusan masalah tersebut, penulis memilih metode penelitian kualitatif dalam rangkaian analisis dan penelitian yang dilakukan. Penelitian kualitatif menghasilkan dan menemukan penemuan-penemuan yang tidak dapat diperoleh dengan menggunakan teknik statistik ataupun cara lain dalam metode kuantitatif. Dalam penelitiannya, metode ini bertujuan untuk menafsirkan fenomena yang sedang terjadi dan bergantung pada pengamatan manusia baik dalam kawasannya ataupun dalam peristilahannya (Albi Anggito \& Johan Setiawan, 2018).

Subjek dari penelitian ini sendiri yaitu adalah Netflix Original Series Netflix dengan judul 13 Reasons Why yang merupakan adaptasi dari novel dengan judul yang 
sama karya Jay Asher. Subjek ini pun diambil dengan pertimbangan bahwa cerita dan pesan yang ada memiliki kaitan serta hubungan dengan realita sosial yang ada dalam kehidupan sehari-hari. Disisi lain, objek yang diambil oleh penulis yaitu adalah bagaimana kekuatan media massa disini yaitu Netflix bisa mempengaruhi perilaku penonton dengan pembingkaian peristiwa akan ketidaksetaraan gender tersebut. Di tahap pengumpulan data akan penelitian ini, penulis melakukan observasi atau pengamatan akan setiap adegan dan peristiwa yang ada di setiap episode. Masuk ke teknik analisis data, penulis memakai teknik analisis wacana kritis Van Dijk. Dalam analisis wacana kritis, wacana tidak hanya dipahami oleh studi bahasa, tetapi bahasa dihubungkan dengan konteks yang ada. Konteks disini berarti bahasa yang dipakai dengan tujuan dan pesan tertentu, serta unsur lainnya seperti pembicaraan, dialog, situasi, dan peristiwa (Eriyanto, 2011).

Penulis juga menggunakan teknik keabsahan data untuk memeriksa keabsahan data dalam hasil penelitian yang penulis lakukan, yaitu teknik triangulasi data. Teknik triangulasi data merupakan teknik pemeriksaan keabsahan data dalam pengujian kredibilitas dan pengecekan data dari berbagai sumber dengan berbagai cara dan waktu.

Dalam penelitian ini terdapat dua sumber data yang mendukung penelitian penulis, yaitu data primer dan data sekunder. Data primer adalah data dari hasil wawancara, pengamatan, serta pencatatan langsung dari materi yang sedang diteliti. Sedangkan data sekunder adalah dokumen-dokumen dan tulisan-tulisan yang sudah ada dan berkaitan dengan penelitian ini.

\section{Hasil Temuan dan Diskusi}

Dalam Netflix Original Series ini, menceritakan kisah seorang remaja bernama Hannah Baker yang telah melakukan bunuh diri dikarenakan oleh perundungan yang ia terima selama di sekolah maupun diluar sekolah. Setelah ia bunuh diri, ia menceritakan alasan ia bunuh diri secara detail dengan mengirimkan paket berisi 13 rekaman kepada 13 teman sekolahnya yang dimana mereka merupakan 13 alasan Hannah Baker akhirnya bunuh diri, maka dari itu serial ini memiliki judul 13 Reasons Why. Di dalam setiap episode dalam 13 Reasons Why, akan terdapat penjelasan mengenai orang-orang yang menjadi alasan Hannah Backer bunuh diri, dan penulis bisa mengetahui 13 penyebab yang berbeda di setiap episodenya, mulai dari perundungan, pertemanan, hingga pelecehan seksual, dan berikut merupakan beberapa karakter dan karakteristik mereka dalam 13 Reasons Why:

Clay Jensen : merupakan teman dekat dari Hannah Baker, ia cenderung memiliki sifat yang tertutup dan mudah mencemaskan suatu hal yang mengganggu pikirannya. Ia juga termasuk anak yang berprestasi di sekolahnya.

Hannah Baker : merupakan remaja yang melakukan aksi bunuh diri di serial ini, disebabkan oleh sakit hati akibat perlakuan teman-temannya kepadanya.

Tony Padilla : adalah teman Clay yang dipercayakan Hannah untuk mengirimkan Kaset pita pesan dari Hannah kepada teman-teman lainnya.

Untuk menjabarkan pesan - pesan yang terkandung dalam Netflix Original Series 13 Reasons Why, penulis membahas karakteristik dari analisis wacana kritis Van Dijk dan menghubungkannya dengan peristiwa yang telah diamati dalam 13 Reasons Why. 
Pada karakteristik pertama, terdapat unsur Tindakan, merupakan suatu kegiatan yang dilakukan untuk sebagai sesuatu yang bertujuan, apakah untuk mempengaruhi, mendebat, membujuk, menyangga, bereaksi, dan sebagainya. Dalam melakukan suatu tindakan, orang pun tidak melakukannya tanpa sadar, melainkan memiliki kesadaran dan kontrol penuh akan suatu tindakan yang dilakukan.

Kedua, Konteks, Wacana di sini dipandang diproduksi, dimengerti, dan dianalisis pada suatu konteks tertentu. Ada 2 konteks yang perlu dimasukan dalam proses analisis wacana ini, yang pertama yaitu partisipan wacana, dimana dilihat gendernya, usia, latar belakang sosial, pendidikan, agama dan hal lain yang berhubungan dengan partisipan wacana. Konteks kedua yaitu, Latar sosial tertentu, seperti tempat, waktu, posisi pembicara dan pendengar atau lingkungan fisik adalah konteks yang berguna untuk mengerti suatu wacana.

Ketiga, Historis, Menempatkan unsur historis sangat penting dalam suatu wacana. Dalam suatu wacana kita harus mengetahui historis terbentuknya wacana tersebut, mengapa bisa terbentuk, awal mula terbentuknya suatu wacana, dan akibat yang terjadi karena peristiwa masa lalu. Jika tidak menempatkan unsur historis didalamnya, semua peristiwa belum tentu bisa dimengerti secara utuh dan belum bisa dipastikan asal usul terbentuknya wacana tersebut.

Keempat, Kekuasaan, semua wacana yang ada dalam bentuk tulisan, peristiwa, tindakan, ataupun percakapan tidak akan muncul begitu saja, melainkan dikarenakan adanya pemakaian unsur kekuasaan dalam bertindak atau mengendalikan suatu peristiwa. Kekuasaan itu dalam hubungannya dengan wacana cukup penting untuk melihat peran mana yang berkuasa dan bisa memulai munculnya suatu wacana.

Kelima, Ideologi, wacana dalam pendekatan ini dipandang sebagai medium melalui mana kelompok yang dominan mempersuasi dan mengkomunikasikan kepada khalayak produksi kekuasaan dan dominasi yang mereka miliki, sehingga tampak absah dan benar. Ideologi disini merupakan dasar perilaku dari suatu kelompok atau individu dalam melakukan suatu atau untuk memunculkan adanya suatu wacana dalam suatu peristiwa dimana mereka merasa benar dengan tindakan yang mereka lakukan.

Setelah melakukan pengamatan akan peristiwa dan adegan yang ada dalam 13 Reasons Why, penulis melakukan proses analisis menggunakan teori yang ada dengan menampilkan adegan atau peristiwa yang berkaitan dengan representasi yang diuji, untuk akhirnya dihubungkan dengan teori.

Episode Pertama (Tersebarnya foto aib Hannah) : Melihat peristiwa yang terjadi di adegan tersebut, penulis dapat menghubungkannya dengan karakteristik teori analisis wacana Van Dijk yaitu unsur tindakan. Tindakan disini merupakan salah satu karakteristik yang menciptakan suatu wacana atau tujuan yaitu mempengaruhi, mengajak, ataupun bereaksi akan suatu hal.

Episode Ketiga (Tulisan di tembok toilet) : Melihat dari peristiwa yang terjadi di adegan ini, dapat dilihat bahwa adanya penyudutan dan penindasan terhadap gender perempuan, dimana banyak ejekan-ejekan yang sangat negatif dan menjatuhkan harga diri seorang perempuan, padahal belum tentu perempuan yang diejek memang benar seperti apa yang ditulis di tembok toilet tersebut.

Episode Ketiga (Daftar perempuan) : Peristiwa ini menunjukan kembali gender perempuan yang diangkat dalam kemasan yang negatif dan menjatuhkan harga diri perempuan. Unsur Konteks pun disini terlihat jelas bahwa situasi terjadi dengan 
mengangkat latar belakang gender perempuan, karena dalam realita kehidupan jika melihat latar belakang gender yang ada, pria identik melihat fisik dari seorang perempuan, dan disini para pria pun membawa kategori fisik perempuan ke dalam daftar yang mereka nikmati isinya, tetapi tidak dengan sebagian perempuan yang merasa itu menjatuhkan derajat harga diri seorang perempuan, apalagi perempuan yang masuk daftar dan berada di kategori terburuk.

Episode Ketiga (Pelecehan oleh Bryce Walker) : Peristiwa tersebut membawa kita ke adegan dimana Bryce melecehkan seorang Hannah yang dimana yaitu Hannah merupakan perempuan. Dari adegan dan narasi yang ditampilkan, terlihat adanya unsur historis yang menjadi salah satu karakteristik analisis wacana Van Dijk. Unsur historis dapat dilihat pada saat dimana Bryce mengungkit kembali kertas yang berisikan daftar dan menyebut Hannah sebagai bokong terbaik.

Episode Keenam (Pelecehan oleh Marcus) : Pelecehan yang dilakukan oleh Marcus berlandasan pada fakta bahwa banyak rumor tidak menyenangkan akan Hannah yang telah tersebar cukup luas di sekolah, meliputi rumor bahwa Hannah adalah perempuan murahan, apalagi ditambah dengan beredarnya foto aibnya yang disebar oleh Bryce Walker lewat handphone Justin. Dari peristiwa tersebut pun menjurus pada unsur karakteristik analisis wacana yaitu unsur Historis yang membuat suatu wacana bisa terjadi karena adanya kejadian masa lalu yang mempengaruhi wacana tersebut.

\section{Kesimpulan}

Sesuai dengan rumusan masalah dan juga tujuan dari penelitian yang telah dijabarkan oleh penulis di BAB I, penelitian ini ingin menunjukan bahwa apakah benar adanya unsur dan implementasi kesetaraan gender dalam Netflix Original Series berjudul 13 Reasons Why ini. Setelah melakukan pengamatan dan analisa mendalam terhadap Netflix Original Series ini, dapat ditarik kesimpulan sebagai berikut :

- Dalam analisis wacana mengenai Netflix Original Series ini, serial ini mengkomunikasikan wacana ketidaksetaraan gender yang ditunjukkan melalui beberapa unsur ketidaksetaraan gender, yaitu dengan menampilkan beberapa peristiwa yang berkaitan dengan realita ketidaksetaraan gender di masyarakat, yaitu antara lain (1) Pelecehan Seksual (2) Penindasan terhadap perempuan (3) Penurunan harga diri perempuan (4) Mudahnya penilaian terhadap perempuan.

- Penelitian wacana mengenai ketidaksetaraan gender ini disertai oleh realita kehidupan remaja masa kini lewat Netflix Original Series ini. Walaupun memang di Amerika serikat, tempat dimana Netflix Original Series ini diambil sudah lebih bebas daripada negara Indonesia, tetapi tetap saja sudah banyak kasus ketidaksetaraan gender dan bahkan pelecehan seksual yang terjadi diruang lingkup sekolah maupun masyarakat umum.

- Penelitian yang dilakukan ini memiliki kaitan terhadap fakultas penulis yaitu ilmu komunikasi. Komunikasi yang baik perlu diterapkan secara efektif, agar penyampaian pesan tidak terhambat dan mudah dipahami oleh masyarakat. Di sisi lain juga analisis wacana mengenai ketidaksetaraan gender ini ditujukan untuk mempersuasif mahasiswa agar dapat ikut serta dalam mencegah terjadinya isu ketidaksetaraan gender yang terjadi seperti di Netflix Original Series 13 Reasons Why ini. 
Reginald Gusli, Wulan Purnama Sari: Representasi Ketidaksetaraan Gender pada Serial Drama 13 Reasons Why (Analisis Wacana Kritis Van Dijk)

\section{Ucapan Terima Kasih}

Pada kesempatan ini, penulis ingin mengucap syukur kepada Tuhan Yang Maha Esa dan juga orang-orang yang mendukung penulis sehingga penulis dapat menyelesaikan skripsi yang berjudul "Representasi Ketidaksetaraan Gender pada 13 Reasons Why (Analisis Wacana Kritis Van Dijk)" dengan lancar dan tepat pada waktunya.

\section{Daftar Pustaka}

Anggito, Albi., \& Setiawan, Johan (2018). Metodologi Penelitian Kualitatif. Sukabumi : CV Jejak.

Anjungroso, Fajar. (2018, 4 Oktober) Artikel ini telah tayang di Tribunnews.com dengan judul Kalahkan YouTube, Netflix Paling Banyak Sedot Kapasitas Bandwidth Dunia. (Agustus, 22 2019) Tribun News https://www.tribunnews.com/techno/2018/10/04/klaahkan-youtube-netflixpaling-banyak-sedot-kapasitas-bandwidth-dunia.

Eriyanto. (2011). Analisis Wacana Kritis : Pengantar Analisis Teks Media. Yogyakarta : LKiS.

IMDB. (2017, 31 Maret) Informasi mendalam tentang serial Netflix 13 Reasons Why. Oktober, 10 2019. IMDB.

https://www.imdb.com/title/tt1837492/episodes?season=1\&ref_=tt_eps_sn_1

Kurniawan, Olivia. (2017). Analisis Wacana Nasionalisme Dalam Film 5cm. Skripsi Universitas Tarumanagara Jakarta.

Wintarto, Wiwien. (2016, 9 Desember). Berkenalan dengan "Binge Watching". (Agustus, 21 2019) Kompasiana.

https://www.kompasiana.com/komentar/wiwienwintarto/584ad4682b7a6168 39963571/berkenalan-dengan-binge-watching. 